\title{
PERUNTUKAN KAWASAN PESISIR KABUPATEN MAROS, SULAWESI SELATAN SEBAGAI LOKASI PENGEMBANGAN BUDIDAYA TAMBAK RAMAH LINGKUNGAN
}

\author{
Utojo, Akhmad Mustafa, dan Hasnawi \\ Balai Riset Perikanan Budidaya Air Payau \\ Jl. Makmur Dg. Sittaka No. 129, Maros 90512, Sulawesi Selatan \\ E-mail: litkanta@indosat.net.id
}

(Naskah diterima: 18 April 2011; Disetujui publikasi: 15 Juli 2011)

\begin{abstract}
ABSTRAK
Penelitian ini bertujuan untuk mendapatkan potensi kawasan pesisir di Kabupaten Maros, Sulawesi Selatan yang layak sebagai lokasi pengembangan budidaya tambak ramah lingkungan dengan menggunakan teknologi Sistem Informasi Geografi (SIG). Data sekunder yang didapatkan berupa data iklim, data pasang surut, peta Rupabumi Indonesia kawasan Maros skala 1:50.000, citra digital landsat ALOS AVNIR- 2 akuisisi 21 Juni 2008 dan peta bathimetri skala 1:200.000. Data primer didapatkan di lokasi penelitian dengan metode survai berupa kualitas air dan tanah tambak. Sebaran stasiun pengamatan dilakukan secara acak dan sistematik, di mana setiap lokasi pengambilan contoh ditentukan posisi koordinatnya dengan alat Global Positioning System (GPS). Data primer dan sekunder serta data citra satelit digital tersebut dikumpulkan dan dianalisis secara spasial menggunakan SIG. Berdasarkan hasil survai dan evaluasi kelayakan lahan budidaya tambak ramah lingkungan di wilayah pesisir Maros seluas $10.249,1$ ha. Yang berkelayakan sedang $(3.111,4 \mathrm{ha})$ dan rendah $(7.137,7 \mathrm{ha})$, tersebar di Kecamatan Bontoa, Lau, Marusu, dan Maros Baru, masing- masing dituangkan dalam peta prospektif skala 1:50.000.
\end{abstract}

KATA KUNCI: budidaya tambak, kelayakan Iahan, SIG, Kabupaten Maros

ABSTRACT: Site assessment of coastal areas of Maros Regency, South Sulawesi to develope environmentaly-friendly brackishwater pond culture system. By: Utojo, Akhmad Mustafa, and Hasnawi

This research was aimed to determine shore areas in Maros Regency, South Sulawesi as a suitable site for sustainable brackishwater pond culture development by using Geographic Information System (GIS). Secondary data such as weather data, tide data, Indonesian Topographic Maps of Maros area scaled of 1: 50,000, landsat digital image of ALOS AVNIR-2 acquisition date on June 21, 2008 and navigation map scaled 1: 200,000. The primary data (soil and water quality) was collected with field visit in the research sites. Simple systematic random sampling was used to allocate sampling points. Position of a sampling point was measured with global positioning system (GPS). Digital remote sensing (Landsat ALOS) data, secondary data, and field data (soil and water quality) were collected and spatial analysis was conducted using GIS. The potential areas classified as suitable for sustainable brackishwater pond culture development in shore areas of Maros Regency, South Sulawesi are 10,249.1 ha, while 
areas classified as moderate suitability was $3,111.4$ ha and low suiatability was $7.137,7$ ha distributed at Bontoa, Lau, Marusu, and Maros Baru Subdistrict. Each classification was depicted in the prospective map with 1:50,000 scale.

\section{KEYWORDS: brackishwater pond culture, area suitability, GIS, Maros Regency}

\section{PENDAHULUAN}

Usaha kegiatan pengembangan budidaya tambak di kawasan pesisir Kabupaten Maros yang berlandaskan tata ruang wilayah sesuai peruntukannya, diharapkan dapat memberikan kontribusi sangat besar terhadap kesejahteraan masyarakat pesisir, pendapatan daerah, devisa negara dengan tetap terpeliharanya ekosistem pesisir yang ramah lingkungan.

Kawasan pesisir dengan karakteristik geografis yang memiliki dataran rendah kawasan intertidal hingga supratidal yang luas, kualitas fisika kimia tanah dan air yang baik, sesuai dengan teknologi budidaya yang diaplikasikan dan memiliki zonasi mangrove di sepanjang pesisir merupakan potensi alam yang ideal bagi pengembangan budidaya tambak. Potensi kawasan pesisir yang besar harusnya dibarengi dengan peningkatan produksi perikanan budidaya yang besar pula, namun potensi yang cukup besar tersebut belum dapat dimanfaatkan secara maksimal untuk pengembangan kegiatan budidaya tambak. Untuk meningkatkan produksinya, ketersediaan data dan informasi potensi kawasan budidaya tambak yang akurat tentunya sangat diperlukan. Data dan informasi tersebut dapat digunakan sebagai landasan awal dalam mendukung pengelolaan dan pengembangan budidaya tambak yang ramah lingkungan. Kajian potensi kawasan budidaya tambak harus mempertimbangkan berbagai aspek termasuk kualitas tanah dan air yang relatif sesuai untuk hidup dan tumbuh bagi jenis komoditas yang dibudidayakan.

Aktivitas perikanan budidaya yang berbasis lahan, memerlukan persyaratanpersyaratan tertentu yang berbeda satu sama lain. Persyaratan tumbuh atau penggunaan lahan yang diperlukan oleh masing- masing komoditas tersebut dapat dijadikan dasar pertimbangan dalam menyusun kriteria kelayakan lahan (Mustafa et al., 2007).

Secara umum, faktor-faktor yang dipertimbangkan sebagai kriteria kelayakan lahan budidaya tambak meliputi topografi dan hidrologi, kualitas tanah, kualitas air, iklim, infrastruktur dan sosial ekonomi (Salam et al., 2003). Untuk setiap jenis komoditas yang diaplikasikan pada teknologi budidaya tambak intensif dengan padat tebar tinggi dan mutlak menggunakan pakan buatan, tentunya membutuhkan kriteria kelayakan lahan yang mendasar dengan persyaratan daya dukung lahan dan karakteristik lingkungan yang komprehensif serta spesifik.

Menurut Utojo et al. (2009), usaha budidaya tambak udang yang berkelanjutan dapat diartikan dengan kegiatan budidaya tambak udang ramah lingkungan yaitu usaha budidaya yang dalam pengembangannya mempertimbangkan karakteristik biofisik lokasi yang sesuai dengan daya dukung lingkungan wilayahnya.

Pengembangan kawasan budidaya tambak yang tidak berlandaskan pemilihan lokasi yang sesuai dengan kualitas lahan dan teknologi budidaya yang diaplikasikan, tidak hanya mendapatkan produktivitas yang rendah, melainkan juga terjadi penurunan kualitas lingkungan. Kualitas lahan tersebut akan berpengaruh terhadap kesesuaian pemilihan lokasi, pemilihan komoditas yang tepat, dan strategi pengelolaan lahan yang tepat (Anwar, 1990).

Dalam pengembangan kawasan budidaya tambak yang ramah lingkungan, penilaian kelayakan lahan perlu dilakukan untuk menjadi dasar pertimbangan dalam pengambilan keputusan penggunaan lahan di suatu daerah untuk menjamin kelangsungan usaha budidaya tambak dengan mempertimbangkan pembagian wilayah, daya dukung lahan, dan pengelolaan lingkungan. Kajian tentang kelayakan lahan di kawasan budidaya tambak melalui survai, menjadi hal yang vital dalam pengembangan budidaya untuk menentukan karakteristik biofisika kimia tanah dan air di lokasi sesuai dengan daya dukung lahannya sehingga mampu meningkatkan produksi tambak yang maksimal dengan meminimasi 
degradasi mutu lingkungan hasil buangan tambak dan kerusakan ekosistem pesisir sebagai habitat sumberdaya perikanan.

Salah satu aspek penting yang harus diperhatikan dalam rangka pembangunan berkelanjutan yaitu kegiatan pembangunan harus ditempatkan pada lokasi yang secara ekologis sesuai tata ruang dan tidak melebihi kapasitas fungsional ekosistem alam. Kawasan pesisir yang dimanfaatkan sebagai sentra pengembangan budidaya tambak yang ramah lingkungan harus dilandasi dengan perencanaan yang tepat, menyeluruh dan terpadu dengan rencana sektor lainnya, menjaga kelestarian sumberdaya dan lingkungan dengan mempertahankan karakteristik wilayah dan daya dukung lahan tetap stabil serta memperhatikan kepentingan sektor lain (Dahuri et al., 1996).

Penggunaan teknologi Sistem Informasi Geografis (SIG) yang diintegrasikan dengan penginderaan jauh (inderaja) melalui citra satelit, bertujuan untuk mendapatkan data dan informasi secara cepat, akurat dan terkini tentang potensi dan kelayakan lokasi pengembangan budidaya tambak yang disajikan dalam bentuk peta tematik. Hasil penelitian kelayakan lokasi ini diharapkan dapat mengoptimalkan potensi sumberdaya lahan kawasan pesisir di Kabupaten Maros terutama mengenai batasan dan peruntukan yang jelas untuk lokasi pengembangan budidaya tambak.

\section{BAHAN DAN METODE}

Kegiatan riset pemetaan kesesuaian lokasi budidaya tambak dilaksanakan pada bulan April 2010 di kawasan pesisir Kabupaten Maros Provinsi Sulawesi Selatan. Pemilihan lokasi survai sesuai dengan ketetapan tata ruang wilayah pesisir Kabupaten Maros untuk pengembangan budidaya tambak (Anonim, 2003a). Penyusunan tata ruang wilayah tersebut dilakukan dengan memperhatikan morfologi pesisirnya yang meliputi topografi, keragaman Iahan, hidrologi dan iklim, serta aspek penunjang lainnya. Data dan informasi kelayakan lokasi tambak hasil analisis spasial, disajikan dalam bentuk peta tematik.

Penelitian ini menggunakan metode survai yang dirancang berdasarkan Sistem Informasi Geografis (SIG). Pengamatan dan pengambilan sampel di lapangan berdasarkan metode transek dengan menentukan titik-titik pengamatan yang dianggap mewakili kawasan yang disurvai berdasarkan kondisi lokasi dan tingkat keseragaman lokasi (Duivenbooden, 1995). Setiap titik pengamatan dan pengambilan sampel ditentukan posisinya dengan alat Global Positioning System (GPS). Sampel air dan tanah, dianalisis di laboratorium mengacu pada APHA (1992) dan Melville (1993). Sebaran titik stasiun pengamatan di lokasi penelitian disajikan pada Gambar 1.

Data primer yang didapatkan meliputi kualitas tanah (pHF, pHFOX, redoks potensial, pirit, $\mathrm{Fe}, \mathrm{Al}, \mathrm{PO}_{4}$, dan $\mathrm{BOT}$ ), tekstur tanah, kualitas air (salinitas, suhu, $\mathrm{pH}, \mathrm{DO}, \mathrm{NO}_{2}-\mathrm{N}, \mathrm{NH}_{4}^{-}$ $\mathrm{N}, \mathrm{NO}_{3}-\mathrm{N}, \mathrm{PO}_{4}-\mathrm{P}, \mathrm{TSS}$, dan $\mathrm{BOT}$ ), topografi pantai, sumber air laut, amplitudo pasut, sumber air tawar/payau, frekuensi banjir, curah hujan, jalur hijau, dan fasilitas saluran. Faktor penunjang lain yang diamati meliputi akses jalan hingga lokasi, listrik, tenaga kerja, sarana produksi tambak, keamanan, pasar, dan legalitas. Data sekunder berupa peta dasar digital lokasi penelitian. Peta dasar ini bersumber dari hasil scan dan digitasi peta Rupabumi Indonesia skala 1:50.000, lembar 2010- 54; 2010-63; dan 2011- 22; edisi I tahun 1991 keluaran Badan Koordinasi Survai dan Pemetaan Nasional (Bakosurtanal) dan citra landsat digital ALOS AVNIR- 2 akuisisi 21 Juni 2008.

Citra landsat ALOS AVNIR- 2 yang sudah terkoreksi geometrik, terkoreksi radiometrik dan teregistrasi. Penajaman citra dengan modifikasi kontras data citra dengan program "Er Mapper". Untuk mengurangi pengaruh cerah atau gelap dari titik citra di dalam citra, dilakukan penapisan citra. Data citra landsat ALOSAVNIR- 2 memiliki 4 kanal, dengan reduksi kanal yang umum digunakan hanya 3 kanal yaitu kombinasi kanal 321 (Red Green Blue) dari sensor AVNIR-2. Hasil analisis kombinasi kanal 321 (Red Green Blue) tersebut menampakkan secara jelas perbedaan spektral untuk setiap tutupan lahan. Kemudian dilakukan klasifikasi untuk membedakan penggunaan lahan secara tepat dan sesuai peruntukan. Informasi dari peta dasar yang diambil meliputi morfologi dan garis pantai, sungai, garis batas wilayah, jalan, sedimen, mangrove, penggunaan lahan, sebaran penduduk, letak dan nama lokasi, garis ketinggian daratan, dan kedalaman laut. Kriteria yang digunakan sebagai dasar skala penilaian dan bobot kelayakan lokasi untuk budidaya tambak mengacu pada Poernomo (1992). 


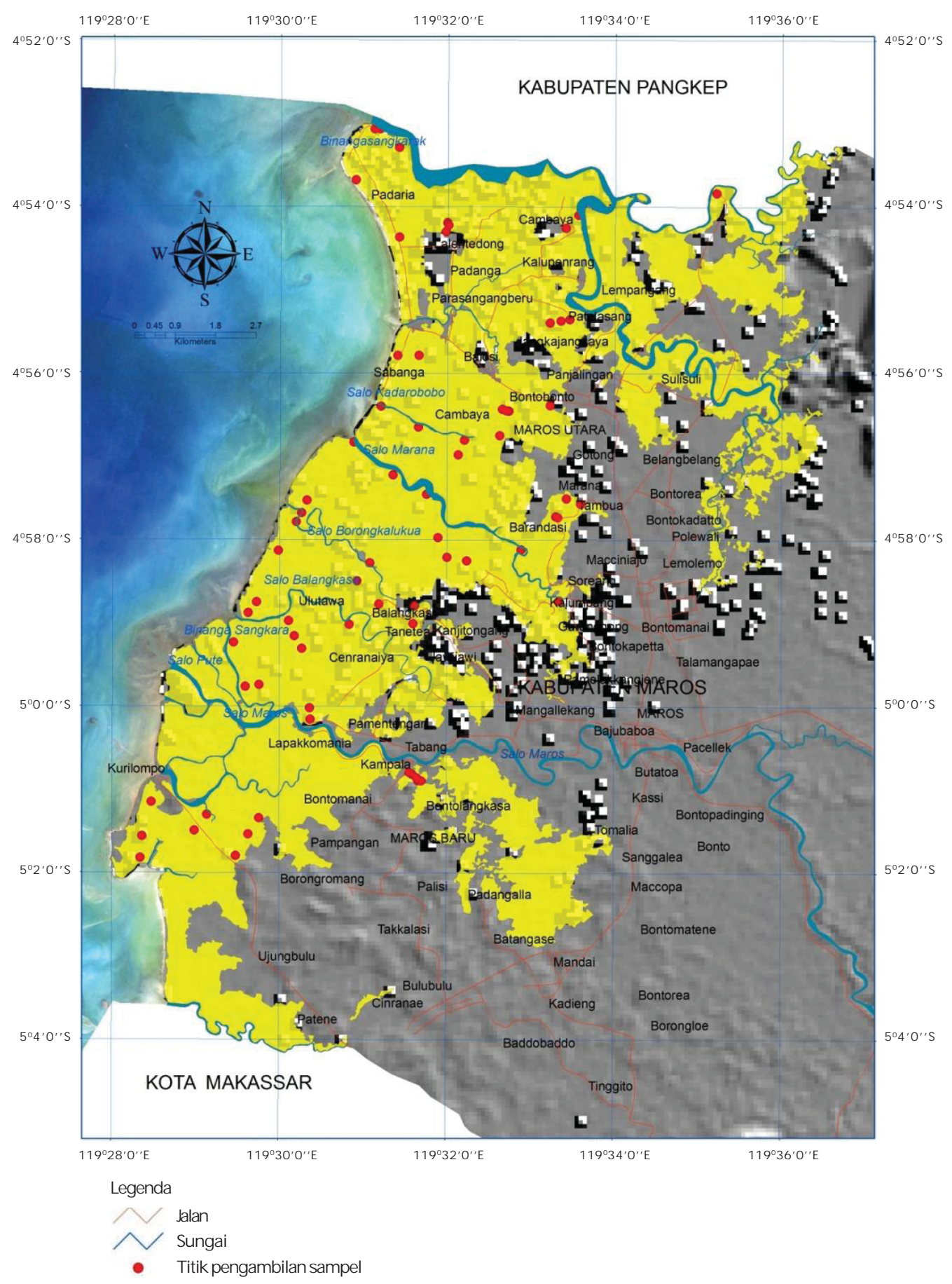

Gambar 1. Peta sebaran stasiun pengamatan kelayakan lokasi budidaya tambak di Kabupaten Maros Sulawesi Selatan

Figure 1. Map of sampling station distribution of the research in Maros Regency South Sulawesi 
Menurut Utojo et al. (2009), penilaian kelayakan lokasi budidaya tambak dilakukan secara kuantitatif melalui skoring dengan faktor pembobot. Nilai total faktor pembobot dari setiap peubah berjumlah 1 . Lokasi budidaya tambak yang masuk kategori kelayakan tinggi (S1) memiliki nilai skala 4, kategori kelayakan sedang (S2) memiliki nilai skala 3, kategori kelayakan rendah (S3) memiliki nilai skala 2 dan kategori tidak layak (N) memiliki nilai skala 1. Analisis secara kuantitatif menggunakan pendekatan:

$$
\mathrm{Y}=\Sigma \text { ai. } \mathrm{Xn}
$$

di mana:

$Y=$ Nilai akhir

ai $=$ Faktor pembobot

$\mathrm{Xn}=$ Nilai tingkat kelayakan lokasi

Untuk mendapatkan selang nilai pada setiap kategori ditentukan dari nilai persentase sebagai berikut: kategori kelayakan tinggi (S1): $\mathrm{Y}=100 \%$ kategori kelayakan sedang (S2): $\mathrm{Y}=$ 75\%-99\% kategori kelayakan rendah (S3): $Y=$ $50 \% 74 \%$ dan kategori tidak layak (N): $\mathrm{Y}=<50 \%$

Skala penilaian pada kategori kesesuaian tinggi (S1), apabila dalam tingkat pengelolaannya sangat didukung oleh peubah biofisik lokasi dan karakteristik lingkungannya, sehingga tingkat produksi yang didapatkan tinggi. Kategori kelayakan sedang (S2), apabila dalam tingkat pengelolaannya mulai terjadi penurunan peubah biofisik lokasi, sehingga untuk mendapatkan tingkat produksi yang tinggi disarankan adanya input teknologi dan kategori kelayakan rendah (S3), apabila dalam tingkat pengelolaannya disertai dengan penurunan peubah biofisik lokasi yang berarti, produksi yang didapatkan rendah sehingga untuk meningkatkan produksi mutlak harus ada input teknologi dan kategori tidak layak (N), apabila lahan memiliki faktor pembatas cukup berat sehingga mencegah kemungkinan pengelolaannya.

Data sekunder dan primer yang sudah dikumpulkan, selanjutnya dilakukan pengolahan data dengan menggunakan analisis spasial dalam Sistem Informasi Geografis (SIG) (Burrough \& McDonnell, 1998). Pada proses analisis dalam komputer dengan program " $A R C$ VIEW 3.3" dengan cara interpolasi yaitu memasukkan setiap peubah data melalui setiap titik pengamatan menjadi area (polygon). Cara interpolasi titik pengamatan menjadi area menggunakan metode "Kriging" (Yost et al.,
1982). Dari hasil interpolasi setiap peubah data yang diperoleh, kemudian disusun dalam bentuk peta tematik.

Kemudian dilakukan overlay (tumpang susun) pada setiap peubah data yang tersusun dalam bentuk peta tematik dengan mempertimbangkan pembobotan dan skala penilaian untuk menentukan tingkat kelayakan lokasi dan peta terkini potensi kawasan pesisir di Kabupaten Maros sebagai peruntukan lokasi pengembangan budidaya tambak.

\section{HASIL DAN BAHASAN}

\section{Kondisi Umum Pesisir}

Dalam pencapaian target produksi sesuai paket teknologi yang diterapkan, tahap awal telah dilakukan survai kelayakan lokasi tambak di 4 kecamatan wilayah pesisir Kabupaten Maros meliputi Kecamatan Bontoa, Lau, Maros Baru, dan Marusu dengan luas tambak yang ada 10.249,1 ha. Secara geografis Kabupaten Maros memilki panjang pantai $36 \mathrm{~km}$ dan terletak pada koordinat antara 119 $20^{\prime} 59^{\prime \prime}-$

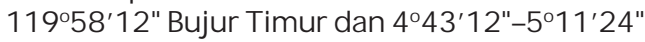
Lintang Selatan, berpotensi sangat baik untuk pengembangan budidaya tambak. Batas wilayahnya sebelah utara berbatasan dengan Kabupaten Pangkep, sebelah timur berbatasan dengan Kabupaten Bone, sebelah selatan berbatasan dengan Kota Makassar, dan sebelah barat berbatasan dengan Selat Makassar.

Topografi daratan pesisir di Kabupaten Maros umumnya landai, terletak berhadapan dengan Selat Makassar yang perairan lautnya terbuka dan dangkal. Memiliki 2 sungai besar yaitu Sungai Maros dan Sungai Binangasangkara serta beberapa sungai kecil seperti Sungai Pajukukang, Sungai Marana, Sungai Kalumpang, Sungai Bawalangiri, Sungai Singkanipisi, Sungai Borongkalukua, dan Sungai Kuri Lompo. Perairan laut dan sungai merupakan sumber air utama bagi pengairan unit pertambakan di kabupaten tersebut. Lokasi pertambakan yang letaknya jauh dari laut dan sungai, menggunakan air tanah sebagai sumber air utamanya. Status lahan pantai saat ini merupakan pertambakan rakyat yang umumnya memiliki bentuk petakan dan saluran tambak yang berbeda serta luas tambak yang bervariasi. Lokasi pertambakan yang letaknya jauh dari laut, berasal dari hasil konversi lahan sawah atau tegalan dan tambak yang letaknya dekat dengan laut sebagian 
besar berasal dari hasil konversi lahan hutan mangrove. Menurut Mustafa et al. (2006), di kawasan pesisir Kabupaten Maros terdapat peningkatan luas tambak dari 7.184,3 ha pada tahun 1991 menjadi 9.818,6 ha pada tahun 2002 atau terjadi peningkatan luas tambak seluas $2.634,3$ ha selama 11 tahun atau 239,5 ha/ tahun. Sebaliknya, terjadi penurunan luas sawah yang ada di kawasan pesisir Kabupaten Maros dari $24.518,0$ ha menjadi $23.418,4$ ha atau terjadi penurunan luas sawah seluas $1.099,6$ ha. Sawah adalah penggunaan Iahan di kawasan pesisir Kabupaten Maros yang paling banyak dikonversi menjadi tambak, sedangkan sisa lahan yang dikonversi menjadi tambak dapat berasal dari jenis penggunaan lain seperti mangrove, ladang, dan belukar. Menurut Faizal (2006), diperkirakan 30\%dari luas mangrove di Indonesia mengalami kerusakan yang berdampak pada degradasi lingkungan, diakibatkan adanya konversi ekosistem mangrove menjadi tambak. Rata- rata setiap unit pertambakan di sepanjang kawasan pesisir Kabupaten Maros terdapat tempat pemukiman. Dikhawatirkan dengan semakin padatnya penduduk yang hidup di kawasan pesisir tersebut akan berpengaruh terhadap menurunnya kualitas lingkungan perairan tambak yang selanjutnya dapat menurunkan produktivitas tambak.

Kabupaten Maros memiliki daratan yang terdiri atas dataran rendah, berbukit, dan bergunung. Dataran rendah yang membentang mulai dari garis pantai barat ke timur berupa tambak, rawa- rawa, tegalan, dan persawahan yang memiliki ketinggian 0-2 $\mathrm{m}$ di atas permukaan laut dengan kelerengan $0 \%-2 \%$ sedangkan daerah perbukitan dan pegunungan dengan ketinggian $100-1.000 \mathrm{~m}$ di atas permukaan laut terletak di sebelah timur berupa batu kapur. Musim hujan terjadi pada bulan Oktober sampai Maret dan musim kemarau terjadi pada bulan April sampai September. Curah hujan di kawasan dataran rendah sampai ke pesisir berkisar $2.000-2.500 \mathrm{~mm} /$ tahun dengan 132 hari hujan/tahun (Anonim, 2009). Karakteristik wilayah yang demikian dan ditunjang dengan daya dukung lahan serta iklim yang memadai, kawasan pesisir Kabupaten Maros dinilai cukup potensial untuk pengembangan kegiatan budidaya tambak.

Pada umumnya wilayah kecamatan pesisir di Kabupaten Maros, memiliki jenis tanah alluvial dengan kondisi lahan yang relatif seragam, sepanjang tepi pantai yang berhadapan dengan laut ditumbuhi mangrove yang didominasi jenis Avicennia sp., dan agak jauh dari laut berturut- turut Sonneratia sp., Bruguiera sp., dan Rhizophora sp. dengan lebar jalur hijau berkisar 30-100 m. Di sepanjang sungai, yang vegetasinya didominasi oleh jenis Nypa sp. dengan kondisi tanah berbahan organik tinggi, pH rendah, kandungan $\mathrm{Fe}$, dan Al serta pirit yang tinggi, lokasi tersebut dinilai kurang potensial untuk kegiatan pertambakan. Umumnya lokasi di sepanjang laut, karena jangkauan air pasang laut yang memudahkan untuk proses remediasi tanah tambak, dinilai cukup potensial untuk kegiatan budidaya tambak. Mangrove yang didominasi oleh Avicennia marina, Nypa fruticans, Rhizophora stylosa, Rhizophora mucronata, dan Sonneratia alba di Kabupaten Maros dijumpai di pesisir pantai dan pinggir sungai (Anonim, 2003b).

Kondisi lahan tambak di lokasi survai, terutama di bekas hutan mangrove yang memiliki kandungan pirit, $\mathrm{Fe}$, dan $\mathrm{Al}$ di kedalaman 20 dan $40 \mathrm{~cm}$ seperti yang disajikan pada Tabel 1.

Nilai kandungan pirit tanah tambak yang tergolong tinggi dengan kedalaman $20 \mathrm{~cm}$ didapatkan di Kecamatan Lau (8,18\%), sedangkan di kecamatan lain tergolong sedang yaitu di Kecamatan Maros Baru (2,84\%), Marusu $(3,74 \%)$, dan Bontoa $(4,99 \%$ ). Nilai kandungan pirit tanah tambak yang tergolong tinggi dengan kedalaman $40 \mathrm{~cm}$ didapatkan di 3 kecamatan yaitu Kecamatan Marusu $(6,42 \%$, Bontoa $(6,43 \%)$, dan Lau $(6,80 \%)$ serta yang tergolong sedang di dapatkan di Kecamatan Maros Baru (4,17\%). Kandungan pirit tanah tambak yang terdapat pada kedalaman 20 $\mathrm{cm}$ dan $40 \mathrm{~cm}$ konsentrasinya berbeda, tergantung dari arah, kecepatan arus sungai dan kecepatan pengendapan. Terdapatnya kandungan pirit dalam tanah tambak kemungkinan disebabkan adanya tanah sulfat masam yang berasal dari erosi lahan di bagian hulu terbawa bersama sedimen melalui aliran sungai dan mengendap di kawasan pesisir yang ditumbuhi tanaman mangrove. Menurut Poernomo (1992), tanah di kawasan mangrove umumnya berpirit dan setelah pengeringan (teroksidasi), memiliki kisaran pH 2,5-5,0.

Nilai kandungan besi tanah tambak di kedalaman $20 \mathrm{~cm}$ yang tergolong tinggi yaitu di Kecamatan Bontoa $(4.718,00$ mg/ L), Lau 
Tabel 1. Kisaran nilai kandungan pirit, Fe, dan Al dalam tanah tambak dengan kedalaman 0- $20 \mathrm{~cm}$ dan 20-40 cm di 4 kecamatan pesisir Kabupaten Maros, Sulawesi Selatan

Table 1. Value ranges of pyrite, $\mathrm{Fe}$, and $\mathrm{Al}$ content in brackishwater pond with sample depth of $0-20 \mathrm{~cm}$ and $20-40 \mathrm{~cm}$ at 4 shore subdistricts of Maros Regency, South Sulawesi

\begin{tabular}{lcccc}
\hline \multirow{2}{*}{$\begin{array}{l}\text { Kecamatan } \\
\text { Subdistrict }\end{array}$} & $\begin{array}{c}\text { Kedalaman } \\
\text { Depth }(\mathbf{c m})\end{array}$ & $\begin{array}{c}\text { Kisaran nilai peubah kimia tanah tambak } \\
\text { Value range of brackishwater pond soil } \\
\text { chemical parameters }\end{array}$ \\
\cline { 2 - 5 } & & $\begin{array}{c}\text { Pirit (Pyrite)(\%) } \\
\text { Fe (mg/ L) }\end{array}$ & A ( mg/ L) \\
\hline Bontoa & $0-20$ & $0.00-4.99$ & $58.00-4,718.00$ & $3.00-503.50$ \\
& $20-40$ & $0.00-6.43$ & $12.00-4,850.50$ & $0.45-491.50$ \\
\hline Lau & $0-20$ & $0.08-8.18$ & $63.00-4,649.00$ & $50.20-491.50$ \\
& $20-40$ & $0.00-6.80$ & $14.50-4,761.50$ & $11.50-568.00$ \\
\hline Maros Baru & $0-20$ & $0.00-2.84$ & $22.50-4,779.00$ & $13.00-789.00$ \\
& $20-40$ & $0.00-4.17$ & $27.50-4,773.00$ & $4.50-795.50$ \\
\hline Marusu & $0-20$ & $0.00-3.74$ & $27.50-4,600.50$ & $13.00-598.50$ \\
& $20-40$ & $0.00-6.42$ & $25.00-4,684.50$ & $0.00-1,249.00$ \\
\hline
\end{tabular}

(4.649,00 mg/ L), Maros Baru (4.779,00 mg/ L), dan Marusu $(4.600,50 \mathrm{mg} / \mathrm{L})$, sedangkan kandungan aluminium yang tergolong tinggi hanya di Kecamatan Maros Baru (789,00 $\mathrm{mg} / \mathrm{L}$ ). Kandungan besi tanah tambak di kedalaman $40 \mathrm{~cm}$ yang tergolong tinggi yaitu di Kecamatan Bontoa $(4.850,50 \mathrm{mg} / \mathrm{L}$, Lau $(4.761,50 \mathrm{mg} / \mathrm{L})$, Maros Baru $(4.773,00 \mathrm{mg} / \mathrm{L})$, dan Marusu $(4.684,50 \mathrm{mg} / \mathrm{L})$, sedangkan kandungan aluminium yang tergolong tinggi yaitu di Kecamatan Bontoa (491,50 mg/ L), Lau (568,00 mg/ L), dan Maros Baru (795,50 mg/ L), kecuali di Kecamatan Marusu (1.249,00 mg/ L), tergolong tertinggi didapatkan pada kawasan tambak yang didominasi vegetasi nipa. Tingginya kandungan besi dan aluminium tanah tambak yang didapatkan akibat dari proses reklamasi kawasan pesisir sebagai lokasi pengembangan budidaya.

Tanah-tanah yang bermasalah di lahan pasang surut untuk lokasi budidaya tambak adalah tanah sulfat masam dan tanah gambut. Tanah sulfat masam merupakan tanah endapan yang banyak mengandung besi dan sulfat, bila teroksidasi dalam jangka waktu yang cukup lama dan tanahnya terairi menyebabkan kelarutan beberapa senyawa toksik. Menurut White et al. (1997), konsentrasi pirit di tanah masam yang teroksidasi menghasilkan asam sulfat yang berasam kuat dan mampu meningkatkan kemasaman secara mendadak dalam tambak dan berdampak pada menurunnya kualitas lingkungan. Lahan seperti ini bila dibangun tambak, produksi awalnya sangat rendah sehingga perlu dilakukan remediasi untuk meningkatkan kualitas lahan.

Aspek dan fasilitas infrastruktur di kawasan pertambakan Kabupaten Maros, dekat dengan jalan raya yang dapat dilalui kendaraan roda empat yang menghubungkan kota Maros dan Makassar, terdapatnya sentra pembenihan udang, pabrik pakan, pabrik es, dan pengumpul udang di Maros dan Makassar sehingga dapat memudahkan di dalam pengangkutan dan pengadaan benih udang, serta sarana produksi tambak saat operasional budidaya dan produksi udang dari hasil budidaya saat panen hingga pemasaran. Pada umumnya saat panen udang, biasanya pengumpul datang ke lokasi tambak langsung membeli ke pembudidayanya, pengumpul tersebut menjual udang ke eksportir di Makassar, kemudian siap untuk diekspor. Di lokasi survai relatif aman dan terdapat kemudahan dalam mendapatkan tenaga kerja baik kuantitas maupun kualitasnya dalam bidang pertambakan. 


\section{Tanah Tambak}

Sebanyak 133 contoh tanah hasil survai yang didapatkan di kedalaman $20 \mathrm{~cm}$ dan 40 $\mathrm{cm}$, terutama tekstur dan kualitas tanahnya, penting untuk menentukan kelayakan lokasi tambak di Kabupaten Maros, disajikan pada Tabel 2. Hasil analisis tekstur tanah pada kedalaman $0-20 \mathrm{~cm}$ dan $20-40 \mathrm{~cm}$ cukup bervariasi. Tekstur tanah yang didominasi oleh fraksi lempung dan liat, didapatkan di lokasi tambak bekas sawah, lahan kosong atau tegalan, sedangkan fraksi pasir, didapatkan di lokasi tambak bekas mangrove. Menurut Poernomo (1992), tekstur tanah tambak yang baik untuk budidaya udang tradisional yaitu lempung liat berpasir, sedangkan tekstur tanah tambak sistem semiintensif dan intensif yaitu lempung liat berpasir hingga lempung berpasir. Lokasi tambak yang bertekstur dominan pasir atau karang, tidak layak untuk kegiatan pertambakan.

Kisaran nilai $\mathrm{pH}$ tanah tambak yang didapatkan pada kedalaman $0-20 \mathrm{~cm}(6,11-7,82)$ dan pada kedalaman $20-40 \mathrm{~cm}(5,85-7,87)$ relatif sama. Kondisi $\mathrm{pH}$ tanah tersebut didapatkan di pertambakan yang telah lama beroperasi. Kisaran nilai pHFOX tanah tambak yang didapatkan pada kedalaman $0-20 \mathrm{~cm}$ $(0,00-6,99)$ dan pada kedalaman $20-40 \mathrm{~cm}$ $(0,26-7,16)$. Rendahnya pHFOX tanah tambak pada kedalaman $0-20 \mathrm{~cm}(0,00)$, dan kedalaman 20-40 cm $(0,26)$, didapatkan pada lokasi tambak mangrove yang telah direklamasi dan memiliki kandungan pirit tinggi $(6,80 \% 8,18 \%$, sedangkan sampel tanah tambak yang didapatkan di lokasi tambak bekas sawah, lahan kosong atau tegalan, memiliki kandungan pirit yang sangat rendah bahkan sampai 0,00\%dan pHFOX tinggi berkisar 6,99-7,16.

Nilai oksidasi dan reduksi potensial tanah yang didapatkan di lokasi survai di kedalaman 0-20 cm berkisar (-66)-(- 387) mV dan kedalaman $20-40 \mathrm{~cm}$ berkisar (-48)-(- 386) $\mathrm{mV}$. Secara alami proses remediasi kondisi tanah di lokasi survai masih layak untuk kegiatan budidaya tambak. Variasi nilai oksidasi dan reduksi potensial tanah sesuai dengan letak pengambilan sampel dan pengukuran di lokasi survai. Kondisi dasar tambak yang baik diperlukan nilai redoks potensial minimal plus (+) $50 \mathrm{mV}$ dengan nilai pH 6,5-8,5 (Boyd dalam Widigdo, 2003). Proses reduksi sulfat terjadi pada kondisi redoks potensial $(E h)=200-300$ $\mathrm{mV}$, sedangkan reduksi besi terjadi pada kondisi redoks potensial (Eh) $=180 \mathrm{mV}$ (Noor, 2004).
Konsentrasi Fe dan Al tanah tambak di lokasi survai di kedalaman 0-20 cm berkisar 22,50-4779,00 mg/ L dan 3,00-789,00 mg/ L, sedangkan di kedalaman $20-40 \mathrm{~cm}$ berkisar 12,00-4835,50mg/ L, dan 0,00-1249,00 mg/ L. Kisaran nilai konsentrasi Fe dan Al tanah tersebut masih baik untuk kegiatan budidaya tambak. Untuk menghilangkan kemasaman dan konsentrasi Fe dan Al di dasar tambak dengan penjemuran, perendaman dan pencucian tambak. Tingginya nilai konsentrasi Fe dan Al di kedalaman tanah $0-20 \mathrm{~cm}$ dan $20-40 \mathrm{~cm}$, didapatkan di kawasan tambak bekas mangrove yang memiliki konsentrasi pirit tinggi $(6,80 \%-8,18 \%)$, sedangkan di tambak bekas sawah, lahan kosong atau tegalan sampai kedalaman $40 \mathrm{~cm}$ tidak didapatkan Fe dan Al karena tanahnya tidak mengandung pirit. Tanah tambak yang mengandung pirit, apabila kondisinya kering akan teroksidasi dan terjadi penurunan $\mathrm{pH}$ yang berdampak pada peningkatan kelarutan Al seperti terlihat pada Tabel 2.

Nilai kandungan fosfat di tanah tambak dengan kedalaman 0-20 cm berkisar 11,51$151,91 \mathrm{mg} / \mathrm{L}$ dan di kedalaman $20-40 \mathrm{~cm}$ berkisar 11,85-122,20 mg/ L di lokasi survai tergolong rendah sampai tinggi, namun masih baik untuk kegiatan budidaya tambak tradisional. Menurut Karthik et al. (2005), ketersediaan fosfat tanah $>60 \mathrm{mg} / \mathrm{L}$, tergolong baik untuk budidaya tambak tradisional, sedangkan lokasi dengan kandungan fosfat tanah yang rendah, baik untuk budidaya tambak intensif.

Kisaran nilai kandungan bahan organik tanah di lokasi survai dengan kedalaman 0-20 $\mathrm{cm}$ yaitu $0,65 \% 25,37 \%$ dan di kedalaman 20 $40 \mathrm{~cm}$ yaitu $0,00 \%-26,68 \%$ masih baik untuk kegiatan budidaya tambak. Menurut Boyd et al. (2002), kisaran nilai bahan organik tanah yang baik untuk budidaya tambak yaitu $1,7 \%$ $5,2 \%$ Kandungan bahan organik tanah yang tinggi, baik untuk budidaya tambak tradisional. Kandungan bahan organik yang rendah, didapatkan di lokasi tambak bekas sawah, Iahan kosong atau tegalan yang ditumbuhi alangalang. Kandungan bahan organik tanah yang rendah, baik untuk kegiatan budidaya tambak intensif.

\section{Sumber Air untuk Pertambakan}

Wilayah pertambakan di Kabupaten Maros rata- rata memiliki sumber air yang cukup menunjang untuk kegiatan budidaya tambak. 


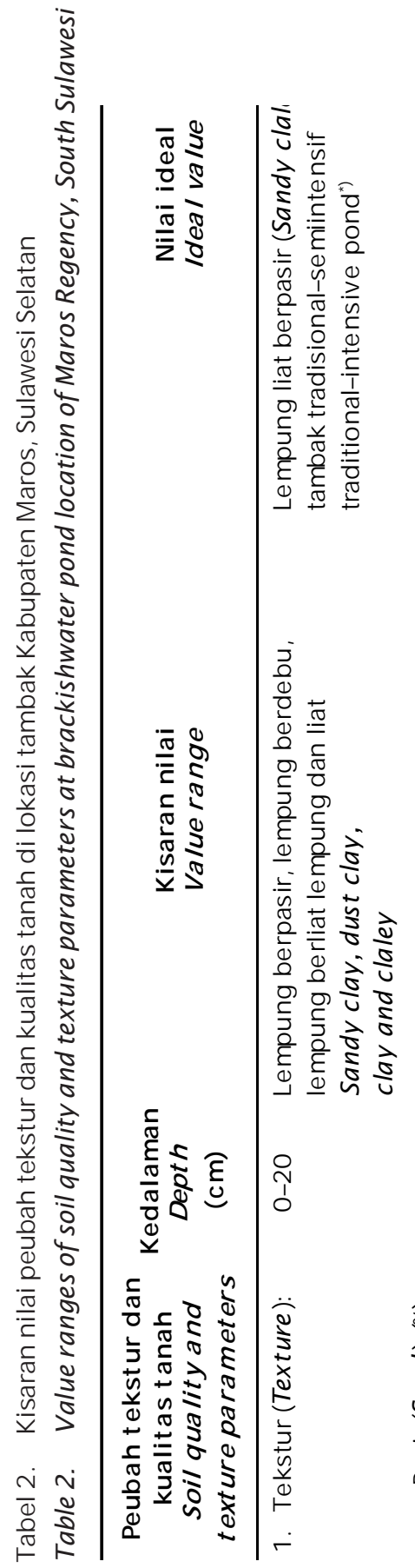

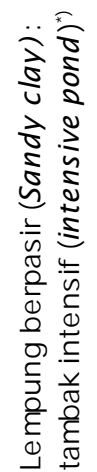

일 일

产 亭 $\frac{\vec{a}}{4}$

完

$\frac{0}{2} \frac{1}{2} \frac{1}{5}$

잉

응 응

5

क्षे

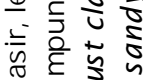

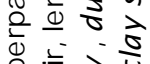

군

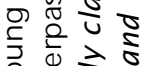

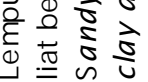

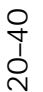

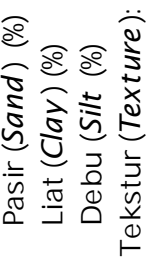

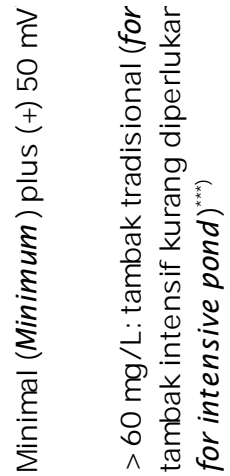

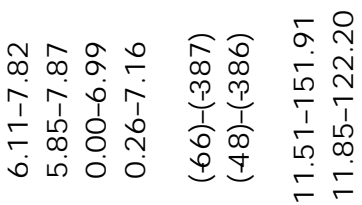

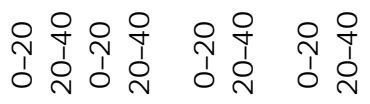

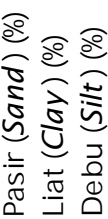




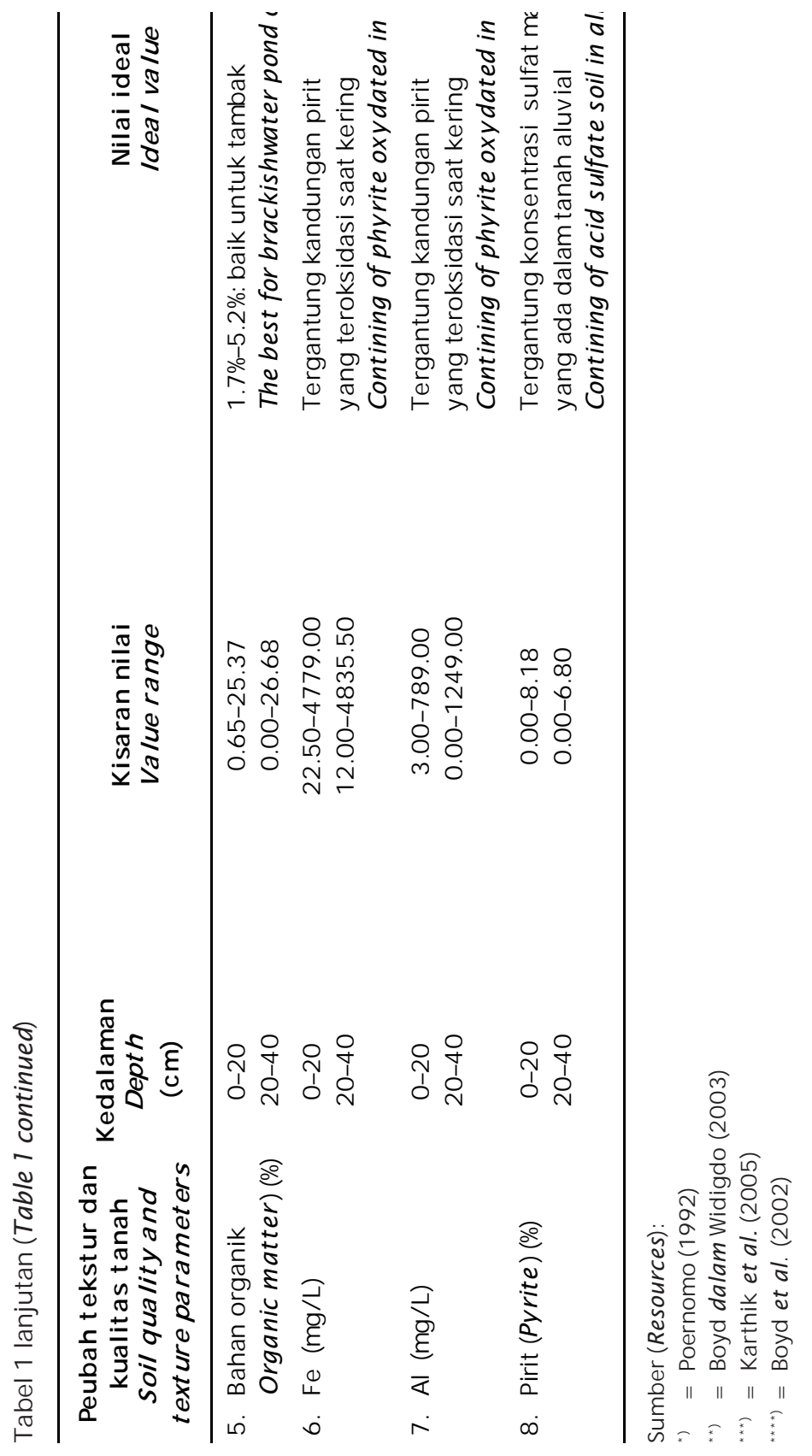


Pada umumnya semua unit pertambakan masih terjangkau pasang surut air laut, hanya unit pertambakan yang letaknya jauh dari laut, airnya relatif tawar, yang menyebabkan salinitas air dalam setiap unit pertambakan bervariasi (Tabel 3). Lokasi pertambakan yang letaknya dekat laut, hasil konversi mangrove dan sumber airnya berasal dari laut bersalinitas 26,76-28,00 ppt dan muara sungai bersalinitas 21,08-26,77 ppt. Lokasi pertambakan yang letaknya agak jauh dari laut, hasil konversi tegalan dan lahan kosong, sumber airnya berasal dari sungai bersalinitas 10-25 ppt. Lokasi pertambakan yang jauh dari laut, hasil konversi sawah dan sumber airnya dari air tanah yang dalamnya 15 m bersalinitas 2,369,00 ppt, seperti di beberapa desa pada Kecamatan Bontoa. Lokasi pertambakan di Desa Tumikamaseang Kecamatan Bontoa, terdapat sumur artesis yang airnya bersalinitas 25 ppt dan digunakan untuk kegiatan penggelondongan dan pertambakan udang windu dan bandeng.

Hasil analisis pasang surut di lokasi survai menunjukkan perbedaan pasang surut yang cukup besar yaitu 182 dan $322 \mathrm{~cm}$ dengan tunggang pasang $140 \mathrm{~cm}$. Kondisi tersebut cukup berpengaruh terhadap kualitas perairan tambak. Secara alami, wilayah dekat pantai yang elevasinya 0-2 $\mathrm{m}$, posisinya lebih rendah dari rataan pasang tertinggi yaitu $322 \mathrm{~cm}$ dan lebih tinggi dari rataan surut terendah yaitu $182 \mathrm{~cm}$, lokasi tambak yang demikian secara gravitasi cukup baik untuk pembangunan unit pertambakan yaitu saat reklamasi untuk pembangunan tambak, saat persiapan tambak dan panen dapat dikeringkan dengan tuntas dan saat pelaksanaan tambak dapat dimasukkan air dengan debet air yang cukup. Menurut Poernomo (1992), budidaya ekstensif dan semiintensif di kawasan intertidal yang pergantian airnya berdasarkan gravitasi, elevasinya sedang, dan dapat diairi oleh rataan pasang tinggi dan dapat dikeringkan saat rataan surut rendah merupakan lokasi yang ideal bagi pembangunan pertambakan.

Suhu air yang didapatkan di lokasi survai berkisar $29,29^{\circ} \mathrm{C}-36,89^{\circ} \mathrm{C}$. Tingginya nilai suhu tersebut didapatkan di pertambakan tradisional yang relatif dangkal dan kisaran nilai suhu tersebut masih baik untuk kegiatan budidaya tambak. Menurut Poernomo (1992), suhu air optimum tambak udang berkisar $29^{\circ} \mathrm{C}$ $31^{\circ} \mathrm{C}$, konsumsi oksigen udang meningkat seiring dengan meningkatnya suhu serta udang tumbuh pesat pada suhu $30^{\circ} \mathrm{C}-31^{\circ} \mathrm{C}$. Suhu air tambak bandeng berkisar $20^{\circ} \mathrm{C}-43^{\circ} \mathrm{C}$.

Nilai $\mathrm{pH}$ air yang didapatkan di lokasi survai berkisar 7,48-10,03. Kisaran nilai pH air tersebut masih baik sebagai media budidaya tambak. Pada tambak yang lama beroperasi, pHnya berkisar 7,5-8,5 dan tambak baru bekas mangrove yang belum direklamasi, $\mathrm{pH}$ - nya di bawah 5. Pengaruh $\mathrm{pH}$ rendah, udang kropos dan selalu lembek, pH tinggi, terjadi peningkatan kadar ammonia yang mematikan udang. Nilai $\mathrm{pH}$ air optimum tambak udang berkisar 8,0-8,5 (Poernomo, 1988).

Nilai kadar oksigen yang terlarut di lokasi survai berkisar 2,32-11,72 mg/ L. Kisaran nilai kadar oksigen tersebut masih baik untuk kegiatan budidaya tambak. Kisaran nilai kadar oksigen tersebut, didapatkan di pertambakan tradisional yang airnya relatif dangkal dan banyak tanaman air. Kadar oksigen terlarut harian yang sangat berfluktuatif, dapat memperlambat pertumbuhan udang. Kadar oksigen terlarut $2,1 \mathrm{mg} / \mathrm{L}$ pada suhu $30^{\circ} \mathrm{C}$, menunjukkan batas kritis minimum kehidupan udang di tambak (Poernomo, 1988).

Kisaran nilai kadar amoniak $\left(\mathrm{NH}_{4}\right)$ di lokasi survai yaitu $<0,0025-1,5225 \mathrm{mg} / \mathrm{L}$ dan masih baik untuk kegiatan budidaya tambak. Kadar amoniak air optimum tambak udang yaitu $0,25 \mathrm{mg} / \mathrm{L}$ (Poernomo, 1992). Tingginya kadar amoniak (1,5225 mg/L), didapatkan di pertambakan tradisional yang dangkal, banyak kelekap dan lumut yang mati serta dasar tambak berwarna hitam. Kadar $\mathrm{NH}_{3}-\mathrm{N} \mathrm{0,05-0,2} \mathrm{mg/} \mathrm{L}$ sudah menghambat laju pertumbuhan organisme akuatik. Menurunnya kadar amoniak dapat disebabkan oleh aktivitas aerasi, pengenceran di dalam tandon, proses nitrifikasi oleh bakteri Nitrobacter dan Nitrosomonas dan penyerapan plankton di tambak (Poernomo, 1988).

Nilai kandungan nitrit $\left(\mathrm{NO}_{2}-\mathrm{N}\right)$ di lokasi survai berkisar $<0,0008-0,0705 \mathrm{mg} / \mathrm{L}$. Kisaran nilai tersebut masih baik untuk kegiatan budidaya tambak. Tingginya nilai kandungan nitrit $(0,0705 \mathrm{mg} / \mathrm{L})$, didapatkan di tambak baru bekas mangrove dan tanaman pantai. Konsentrasi nitrit yang aman bagi kehidupan udang adalah $<0,1 \mathrm{mg} / \mathrm{L}$ dan optimum adalah 0,25 mg/ L (Poernomo, 1992).

Nilai kandungan nitrat $\left(\mathrm{NO}_{3}-\mathrm{N}\right)$ di lokasi survai berkisar $<0,0015-0,7810 \mathrm{mg} / \mathrm{L}$. Kisaran nilai tersebut masih baik untuk kegiatan budidaya tambak. Tingginya kandungan nitrat 
Tabel 3. Kisaran nilai peubah kualitas air di lokasi tambak Kabupaten Maros, Sulawesi Selatan

Table 3. Value ranges of water quality parameters at brackishwater pond location of Maros Regency, South Sulawesi

\begin{tabular}{|c|c|c|c|}
\hline $\begin{array}{c}\text { Peubah kualitas air } \\
\text { Water quality parameters }\end{array}$ & $\begin{array}{l}\text { Satuan } \\
\text { Unit }\end{array}$ & $\begin{array}{l}\text { Kisaran nilai } \\
\text { Value range }\end{array}$ & $\begin{array}{l}\text { Nilai ideal } \\
\text { Ideal value }\end{array}$ \\
\hline \multicolumn{4}{|l|}{ Salinitas (Salinity): } \\
\hline - Laut & ppt & $26.76-28.00$ & $30-35^{*}$ \\
\hline - Muara sungai & ppt & $21.08-26.77$ & $10-20^{*}$ \\
\hline - Tambak & ppt & $3.24-20.57$ & $15-25^{*}$ \\
\hline - Air tanah & & $2.36-9.00$ & - \\
\hline Suhu air (Water temperature) & ${ }^{\circ} \mathrm{C}$ & $29.29-36.89$ & $29-31^{*}$ \\
\hline $\mathrm{pH}$ & & $7.48-10.03$ & $7.0-8.5^{* *}$ \\
\hline Tunggang pasang surut (Tide) & $\mathrm{cm}$ & 140 & - \\
\hline Oksigen terlarut (Dissolved oxygen) & $\mathrm{mg} / \mathrm{L}$ & $2.32-11.72$ & $4-7^{*)}$ \\
\hline $\mathrm{NH}_{4}-\mathrm{N}$ & $\mathrm{mg} / \mathrm{L}$ & $<0.0025-1.5225$ & $0.30^{* *}$ \\
\hline $\mathrm{NO}_{2}-\mathrm{N}$ & $\mathrm{mg} / \mathrm{L}$ & $<0.0008-0.0705$ & $0.25^{*}$ \\
\hline $\mathrm{NO}_{3}-\mathrm{N}$ & $\mathrm{mg} / \mathrm{L}$ & $<0.0015-0.7810$ & $0.008^{* *}$ \\
\hline $\mathrm{PO}_{4}-\mathrm{P}$ & $\mathrm{mg} / \mathrm{L}$ & $0.0062-0.6012$ & $0.015^{* *}$ \\
\hline $\begin{array}{l}\text { Padatan tersuspensi total } \\
\text { Total suspended solute }\end{array}$ & $\mathrm{mg} / \mathrm{L}$ & $3-209$ & - \\
\hline $\begin{array}{l}\text { Bahan organik total } \\
\text { Total organic matter }\end{array}$ & $\mathrm{mg} / \mathrm{L}$ & $2.53-37.75$ & $29.50^{*}$ \\
\hline
\end{tabular}

Sumber (Resources):

*) = Poernomo (1992)

${ }^{* *}=$ Kementerian Lingkungan Hidup (Ministry of Live Environment) (2004)

(0,7810 $\mathrm{mg} / \mathrm{L})$, didapatkan di pertambakan tradisional yang ditumbuhi banyak tanaman air dan kelekap. Di perairan alami, konsentrasi nitrat tidak pernah lebih dari $0,1 \mathrm{mg} / \mathrm{L}$ dan tidak bersifat toksik terhadap organisme akuatik (Effendi, 2003).

Nilai kandungan fosfat $\left(\mathrm{PO}_{4}-\mathrm{P}\right)$ di lokasi survai berkisar 0,0062-0,6012 mg/ L. Kisaran nilai tersebut masih baik untuk kegiatan budidaya tambak. Tingginya nilai tersebut $(0,6012 \mathrm{mg} / \mathrm{L})$, didapatkan di pertambakan tradisional yang dangkal dengan warna air hijau dan terdapat banyak tanaman air, kelekap, dan fitoplankton. Kandungan fosfat di perairan alami berkisar 0,005-0,020 mg/ L dan jarang melebihi 1 mg/ L (Boyd, 1988).

Nilai kandungan bahan organik total dan padatan tersuspensi total di lokasi survai berkisar 2,53-37,75 mg/ L dan 3-209 mg/ L. Kisaran nilai kandungan bahan organik dan padatan tersuspensi total yang didapatkan masih baik untuk kegiatan budidaya tambak, sedangkan tingginya nilai kekeruhan akibat lumpur halus, didapatkan di tambak dekat muara sungai. Pada perairan alami, kandungan bahan organik total di atas $26 \mathrm{mg} / \mathrm{L}$, tergolong subur (Reid, 1961). Kondisi tambak yang demikian baik untuk kegiatan budidaya tambak tradisional, sedangkan pada kegiatan tambak intensif dapat menurunkan kualitas air.

\section{Lokasi Pengembangan Budidaya Tambak}

Hasil analisis spasial kelayakan lokasi budidaya tambak di Kabupaten Maros menggunakan teknologoi SIG, dapat diidentifikasi dan disajikan dalam peta tematik, memiliki kelayakan rendah sampai sedang (Gambar 2). Dari hasil analisis tersebut, dapat diestimasi potensi dan kelayakan tambak di Kabupaten Maros seluas 10.249,1 ha. Yang berkelayakan sedang $(3.111,4$ ha) dan rendah $(7.137,7 \mathrm{ha})$, 


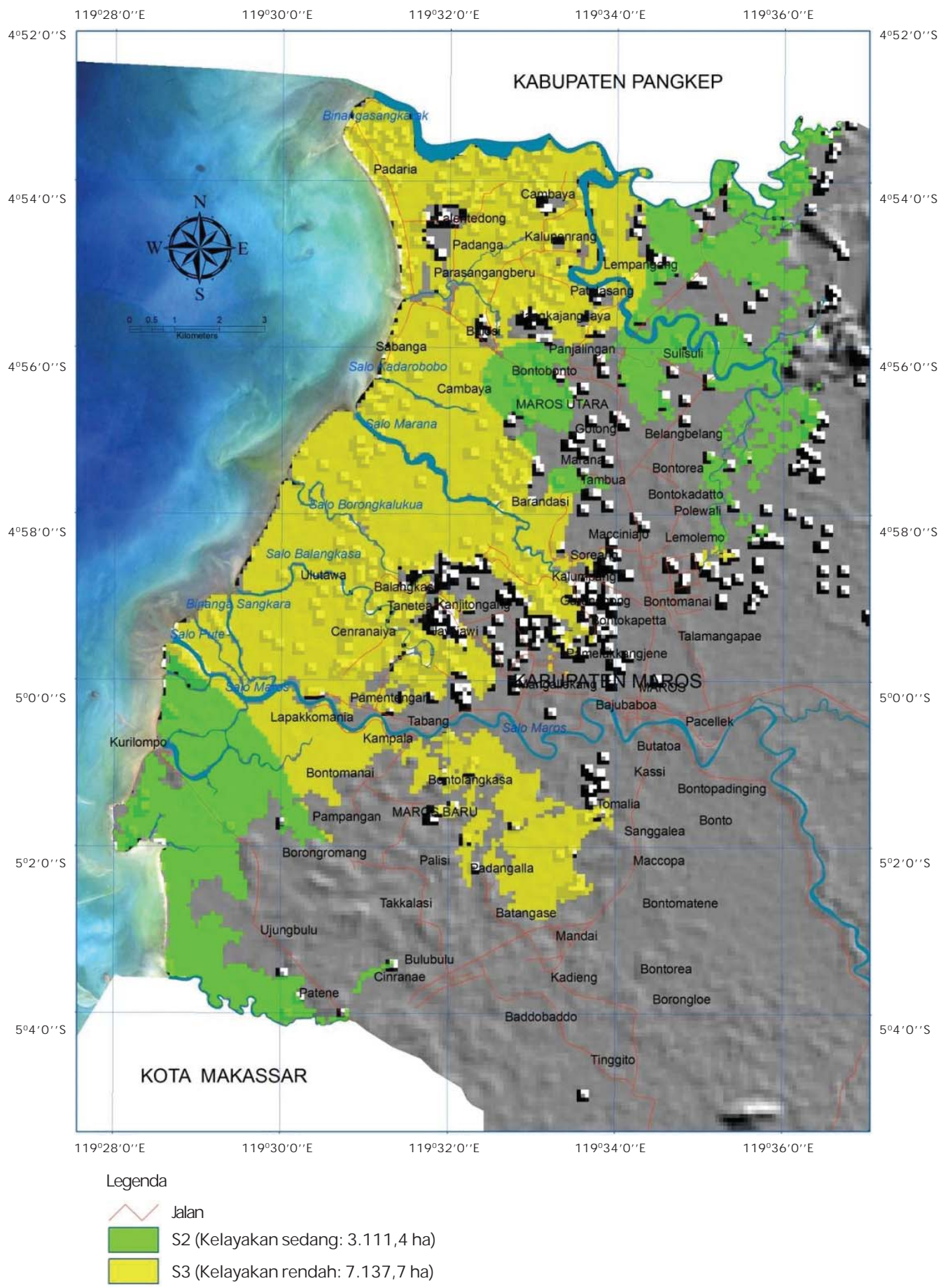

Gambar 2. Peta kelayakan lokasi budidaya tambak di Kabupaten Maros Sulawesi Selatan

Figure 2. Map of suitability for brackishwater pond culture in Maros Regency South Sulawesi 
tersebar di wilayah pesisir Kecamatan Bontoa, Lau, Marusu, dan Maros Baru.

Lebar jalur hijau di sepanjang pantai Kabupaten Maros yang harus diaplikasikan minimal $130 \times$ nilai rata- rata perbedaan air pasang tertinggi dan terendah setempat $(1,4$ $\mathrm{m}$ ) yang diukur dari garis pantai saat air surut terendah yaitu $182 \mathrm{~m}$ dan lebar jalur hijau di tepi sungai minimal berjarak $100 \mathrm{~m}$ dari kiri dan kanan sungai besar serta $50 \mathrm{~m}$ dari kiri dan kanan sungai kecil yang berada di luar pemukiman.

Potensi kawasan pesisir yang telah diidentifikasi, sekitar $55 \%$ dari potensi lahan (10.249,1 ha) yang efektif untuk kegiatan budidaya tambak seluas 5.637,01 ha. Yang memiliki kelayakan sedang 1.711,27 ha dan kelayakan rendah 3.925,74 ha. Lokasi yang memiliki kelayakan sedang, untuk kegiatan tambak udang (monokultur) atau udang bersama bandeng (polikultur) sistem tradisional hingga tradisional plus dan kelayakan rendah untuk kegiatan tambak bandeng (monokultur) atau bandeng bersama rumput laut (polikultur) sistem tradisional.

\section{KESIMPULAN}

Hasil analisis spasial menggunakan SIG menunjukkan bahwa potensi lokasi budidaya tambak di Kabupaten Maros, Sulawesi Selatan, memiliki kelayakan rendah sampai sedang, seluas 10.249,1 ha. Lokasi yang efektif untuk kegiatan budidaya tambak (eksisting) sekitar $55 \%$ dari total potensi lahan yaitu 5.637,01 ha. Lokasi yang memiliki kelayakan sedang (1.711,27 ha) dan rendah $(3.925,74 \mathrm{ha})$, tersebar di Kecamatan Bontoa, Lau, Marusu, dan Maros Baru. Kondisi biofisik, kualitas tanah dan air (peubah fisika dan kimia) di lokasi penelitian masih baik untuk kegiatan budidaya tambak.

\section{DAFTARACUAN}

Anonim. 2003a. Masterplan pengembangan budidaya air payau di Indonesia. Direktorat Jenderal Perikanan Budidaya, Departemen Kelautan dan Perikanan, Jakarta, $250 \mathrm{hlm}$.

Anonim. 2003b. Status Lingkungan Hidup Daerah Kabupaten Maros. Badan Pengendalian Dampak Lingkungan Daerah Maros.

Anonim. 2009. Kabupaten Maros dalam Angka 2009. Maros Regency In Figures 2009. Kerja sama Badan Perencanaan Pem- bangunan Daerah dengan Badan Pusat Statistik Kabupaten Maros, $78 \mathrm{hlm}$.

Anwar, A. 1990. Beberapa konsepsi alokasi sumber daya alam untuk penentuan kebijaksanaan ke arah pembangunan perikanan yang berkelanjutan. www.ikan mania.wordpress.com. Diakses tanggal 19 Maret 2008.

APHA (American Public Health Association). 1992. Standart Methods for the Examinition of Water and Wastewater. American Public Healt Assosiation. Washington, D.C., 874 pp.

Boyd, C.E. 1988. Water Quality in Warmwater Fish Ponds. Fourth Printing. Auburn University Agricultural Experiment Station, Alabama, USA, $359 \mathrm{pp}$.

Boyd, C.E., Wood, C.W., \& Thunjai, T. 2002. Aquaculture Pond Bottom Soil Quality Management. Oregon State University. Corvallis, Oregon, $41 \mathrm{pp}$.

Burrough, P.A. \& McDonnel, R.A. 1998. Principle of Geographical Information Systems. Oxford University Press, 327 pp.

Dahuri, R., Rais, J.R., Ginting, S.P., \& Sitepu, M.J. 1996. Pengelolaan Sumber daya Wilayah Pesisir dan Lautan Secara Terpadu. PT Pradnya Paramita, Jakarta.

Duivenbooden, N.V. 1995. Land Use Systems Analysis as A Tool in Land Use Planning, $176 \mathrm{pp}$.

Effendi, H. 2003. Telaah Kualitas Air Bagi Pengelolaan Sumber daya dan Lingkungan Perairan. Penerbit KANISIUS (Anggota IKAPI), Yogyakarta, $258 \mathrm{hlm}$.

Faizal, A. 2006. Pemetaan luasan dan kerapatan hutan mangrove di Pulau Tanakeke dengan transformasi NDVI. Jurnal Ilmu Kelautan dan Perikanan “Torani”. Edisi Juni 2006. Fakultas Ilmu Kelautan dan Perikanan, Universitas Hasanuddin, Makassar, 16(2): 85- 91.

Yost, R.S., Uehara, G., \& Fox, R.L. 1982. Geostatistical analysis of soil chemical properties of large land areas. II. Kriging. Soil Science Society of American Journal, 46: 1033- 1037.

Karthik, M., Suri, J., Saharan, N., \& Biradar, R.S. 2005. Brackhiswater aquaculture site selection in Palghar Taluk, Thane District of Maharashtra, India, using the techniques of remote sensing and Geographical Information System. Aquaculture Engineering, 32: 285- 302.

Kementerian Lingkungan Hidup. 2004. Keputusan Menteri Negara Lingkungan 
Hidup, No. 51 tahun 2004, tanggal 8 April 2004 tentang Baku Mutu Air Laut. Kementerian Lingkungan Hidup, Jakarta, 11 $\mathrm{hlm}$.

Melville, M.D. 1993. Soil Laboratory Manual School of Geography, University of New South Wales, Sydney, 74 pp.

Mustafa, A., Utojo, Hasnawi, \& Rachmansyah. 2006. Validasi data luas lahan budidaya tambak di Kabupaten Maros dan Pangkep, Provinsi Sulawesi Selatan dengan menggunakan teknologi penginderaan jauh dan sistem informasi geografis. J. Ris. Akuakultur. Pusat Riset Perikanan Budidaya, Jakarta, 3(1): 419- 430.

Mustafa, A., Sapo, I., Hasnawi, \& Sammut, J. 2007. Hubungan antara faktor kondisi lingkungan dengan produktivitas tambak untuk penajaman kriteria kelayakan lahan: 1. kualitas air. J. Ris. Akuakultur. Pusat Riset Perikanan Budidaya, Jakarta, 2(3): 289- 302.

Noor, M. 2004. Lahan Rawa. Sifat dan PengeIolaan Tanah Bermasalah Sulfat Masam. Edisi ke- 1, cetakan 1, PT Raja Grafindo Persada, Jakarta, $229 \mathrm{hlm}$.

Poernomo, A. 1988. Pembuatan Tambak di Indonesia. Seri Pengembangan No. 7, 1988. Departemen Pertanian, Badan Penelitian dan Pengembangan Pertanian, Balai Penelitian Perikanan Budidaya Pantai, Maros, $30 \mathrm{hlm}$.

Poernomo, A. 1992. Pemilihan Lokasi Tambak Udang Berwawasan Lingkungan, CRIFI Pub., $40 \mathrm{hlm}$.

Reid, G.K. 1961. Ecology Inland Water Estuaries. Rein Hald Published Co. New York, 37 $\mathrm{pp}$.

Salam, M.A., Khatun, N.A., \&Ali, M.M. 2003. Carp farming potential in Barhatta Upazilla, Bangladesh: a GIS methodological perspective. Aquaculture, 245: 75- 87.

Utojo, Mustafa, A., Rachmansyah, \& Hasnawi. 2009. Penentuan lokasi pengembangan budidaya tambak berkelanjutan dengan aplikasi sistem informasi geografis di Kabupaten Lampung Selatan. J. Ris. Akuakultur, 4(3): 407-423.

White, I., Melville, M.D., Wilson, B.P., \& Sammut, J. 1997. Reducing acidic discharge from coastal wetlands in estern Australia. Wetlands Ecology and Management, 5: 55- 72.

Widigdo, B. 2003. Permasalahan dalam budidaya udang dan solusinya. Jurnal IImu-IImu Perairan dan Perikanan Indonesia, 10(1): 18-23. 